\title{
Occurrence of cervical intraepithelial neoplasia in generally healthy women with exophytic vulvar condyloma acuminata
}

\author{
OSCAR SADAN ${ }^{1,2}$, EFI BILEVSKY ${ }^{2}$, EDUARDO SHEJTER $^{3}$, TALLY LEVY ${ }^{1,2}$, \\ RACHEL BACHAR ${ }^{3}$, HAVAZELET YARDEN ${ }^{2}$, MAREK GLEZERMAN $^{1,2}$, \\ \& SAMUEL LURIE ${ }^{1,2}$ \\ ${ }^{1}$ Department of Obstetrics and Gynecology, Edith Wolfson Medical Center, Holon, Israel, ${ }^{2}$ Sackler School of Medicine, Tel \\ Aviv University, Tel Aviv, Israel and ${ }^{3}$ Cervical Clinic, Maccabi Health Services, Tel Aviv, Israel
}

(Received 1 fuly 2004; revised 10 November 2004)

\begin{abstract}
Aim. To disclose possible association between exophytic vulvar condyloma acuminata and cervical intraepithelial neoplasia in generally healthy, sexually active women.

Methods. This retrospective study included 74 patients (study group) who were referred for laser vaporization therapy of exophytic vulvar condyloma acuminata, and 88 asymptomatic volunteers without evidence of exophytic vulvar condyloma acuminata (control group) who were referred for screening Papanicolaou (Pap) test cervical evaluation including colposcopy. The diagnosis of cervical intraepithelial neoplasia was based on Pap smear, colposcopy and/or biopsy.

Results. On Pap smear, atypical squamous cells of undetermined significance or low-grade squamous intraepithelial lesions were found in $10(13.5 \%)$ women with exophytic vulvar condyloma acuminata and in $2(2.3 \%)$ asymptomatic volunteers $(p<0.05)$. Cervical intraepithelial neoplasia was found in 8 women with exophytic vulvar condyloma acuminata and in none of the asymptomatic volunteers $(p<0.05)$.

Conclusion. An association was found between exophytic vulvar condyloma acuminata and abnormal Pap smear or positive cervical biopsy, in generally healthy women.
\end{abstract}

Keywords: CIN, condyloma acuminata, $H P V$

\section{Introduction}

Condyloma acuminata (genital warts) is the most common sexually transmitted disease in industrialized countries [1]. It is caused by human papillovirus (HPV) and it produces significant morbidity. HPV types 6 and 11 were found in most genital warts [1]. These HPV types are not associated with high-grade cervical neoplasia [2], but they can cause minor degrees of cervical intraepithelial neoplasia which also result in morbidity both from fear and from overtreatment [1]. The true relationship between genital warts and cervical intraepithelial neoplasia is far from being completely elucidated. For example, in HIVpositive women, genital warts were described as a factor contributing to the development of cervical intraepithelial neoplasia (squamous intraepithelial lesions) [3]. The possibility of mixed infection with several HPV types is well documented; in this case there is a possibility that women with vulvar condyloma are at high risk for cervical intraepithelial neoplasia.

This study was undertaken to find out whether there is an association between exophytic vulvar comdyloma acuminata and cervical intraepithelial neoplasia in generally healthy, sexually active women.

\section{Materials and methods}

The study group comprised 74 women (aged $31.3+/$ -9.2 years) who were referred for laser vaporization therapy of exophytic vulvar condyloma acuminata at the cervical unit of Maccabi Health Services between June 11996 and November 30 2001. The control group comprised 88 asymptomatic volunteers (aged $41.1+/-13.6$ years) who were referred for screening Papanicolaou (Pap) test without evidence of exophy-

Correspondence: S. Lurie, Department of Obstetrics and Gynecology, Edith Wolfson Medical Center, Holon, Israel. Tel: + 97235028329. Fax: +9728 9366259. E-mail: drslurie@hotmail.com

ISSN 1064-7449 print/ISSN 1098-0997 online (C) 2005 Taylor \& Francis Group Ltd DOI: $10.1080 / 10647440500068206$ 
tic vulvar condyloma acuminata. The age difference between the groups was significant statistically $(p<0.05)$. Inclusion criteria in the study group consisted of availability of a Pap smear and/or cervical biopsy that had been performed during the month preceding the referral, no present history of significant disease, and sexually activity. An exclusion criterion was a positive HIV test, and 1 woman was excluded. Colposcopy was performed before laser vaporization therapy to exclude cervical pathology. After the initial analysis, the women were followed up for a period of 18 months for development of cervical intraepithelial neoplasia, using Pap smear and/or colposcopy with biopsy. The inclusion criterion for the control group was sexually activity. A Pap smear and colposcopy were carried out for all volunteers, and biopsy was performed as required for women with suspicious cervical findings on colposcopy. Cervical intraepithelial neoplasia was classified in accordance with Bethesda System terminology [4].

The present study had $80 \%$ power to detect a $10 \%$ difference in the rate of cervical intraepithelial neoplasia (two-sided $\alpha=0.05$ ) at the present sample size. Statistical analysis was performed by Student's $t$ test or chi-square $\left(\chi^{2}\right)$ test as indicated. Significance was set at $p<0.05$.

\section{Results}

Condyloma acuminata was vulvar in 59 (79.7\%), perianal in $10(13,5 \%)$ and unspecified in 5 participants $(6.7 \%)$. On Pap smear, atypical squamous cells of undetermined significance (ASCUS) or low-grade squamous intraepithelial lesions (LGSIL) were found in $10(13.5 \%)$ women with exophytic vulvar condyloma acuminata and in $2(2.3 \%)$ asymptomatic volunteers $(p<0.05)$. No high-grade squamous intraepithelial lesions (HGSIL) were found on Pap smear. Cervical biopsy on colposcopy was undergone by 41 women with exophytic vulvar condyloma acuminata and 14 asymptomatic volunteers (Table I). Cervical intraepithelial neoplasia (CIN) was found in 8 women with exophytic vulvar condyloma acuminata and none of the asymptomatic volunteers $(p<0.05)$.

Table I. Participants' cervical biopsy results. The data are presented as number (percentage). The differences between the groups are statistically significant (chi square $30.7, p<0.001$ ).

\begin{tabular}{lcc}
\hline Result & $\begin{array}{c}\text { Study group } \\
(n=74)\end{array}$ & $\begin{array}{c}\text { Control group } \\
(n=88)\end{array}$ \\
\hline CIN2/CIN3 & $1(1.4 \%)$ & $0(0.0 \%)$ \\
CIN1 & $8(10.8 \%)$ & $0(0.0 \%)$ \\
No dysplasia & $32(43.2 \%)$ & $14(16.9 \%)$ \\
Not performed & $33(44.6 \%)$ & $74(84.1 \%)$ \\
\hline
\end{tabular}

CIN, cervical intraepithelial neoplasia.

\section{Discussion}

We assessed the prevalence of CIN in generally healthy women with exophytic vulvar condyloma acuminata and in asymptomatic volunteers. Mild CIN was found only in women with exophytic vulvar condyloma acuminata. These findings would be classified as LGSIL on Pap smear. The result probably reflects the fact that exophytic vulvar condyloma acuminata are caused by HPV types that are not involved in significant CIN [2]. The converse obtains in HIV-positive women, where genital warts were found to contribute to the development of CIN [3].

Most HPV infections are transient, and only women who harbor a persistent HPV infection are likely to develop a cervical lesion [5]. In general, type-specific HPV infection is cleared within 2 years [6]. During this period, a woman may become reinfected with a new HPV genotype [6]. Therefore, presence of a certain HPV type infection may be a risk factor for the presence of another HPV genotype. This could be the rationale for assessment of CIN for women with exophytic vulvar condyloma acuminata. Similarly, a previous study from Denmark demonstrated an increased prevalence of abnormal Pap smears in women with genital warts [7].

In conclusion, we are in agreement with the concept that women with exophytic condyloma acuminata are at very low risk for developing significant CIN. However, a routine Pap smear for women with exophytic condyloma acuminata is necessary, and women with abnormal findings should undergo colposcopy and biopsy. Although not directly addressed in our study, HPV typing might identify the specific subgroup of women with exophytic condyloma acuminata who might further benefit from colposcopy in addition to Pap smear $[8,9]$.

\section{References}

1. Birley HD. Continuing medical ignorance: modern myths in the management of genital warts. Int J STD AIDS 2001;12:7174.

2. Cannistra SA, Nitoff JM. Cancer of the uterine cervix, N Engl J Med 1996;334:1030-1037.

3. Goncalves MA, Burattini MN, Donadi EA, Massad E. Anogenital warts contributing to the risk of squamous intraepithelial lesions among HIV-positive women of Sao Paulo, Brazil. Int J STD AIDS 2003;14:309-313.

4. The 1991 Bethesda System for reporting cervical/vaginal cytology diagnoses: report of the 1991 Bethesda Workshop. JAMA 1992;277:1892.

5. Hildesheim A, Schiffman M, Gravitt P, Glass AG, Greer CE, Zhang T, Scott DR, Rush BB, Lawler P, Sherman ME, et al. Persistence of type-specific human papillomavirus infection among cytologically normal women. J Infect Dis 1994;169: 235-240. 
6. Richardson H, Kelsall G, Tellier P, Voyer H, Abrahamowicz M, Ferenczy A, Coutlee F, Franco EL. The natural history of type-specific human papillomavirus infections in female university students. Cancer Epidemiol Biomarkers Prev 2003; 12:485-490.

7. Munk C, Svare EI, Poll P, Bock JE, Kjaer SK. History of genital warts in 10,838 women 20 to 29 years of age from the general population. Risk factors and association with Papanicolaou smear history. Sex Transm Dis 1997;24:567-572.
8. Zehbe I, Strand A, Chua KL, Wilander E. Cytological evaluation and molecular human papillomavirus test of cervical scrapings from women treated for condyloma. Gynecol Obstet Invest 1996;42:128-132.

9. Cuzick J, Szarewski A, Cubie H, Hulman G, Kitchener H, Luesley D, McGoogan E, Menon U, Terry G, Edwards R, et al. Management of women who test positive for high-risk types of human papillomavirus: the HART study. Lancet 2003;362: $1871-1876$ 


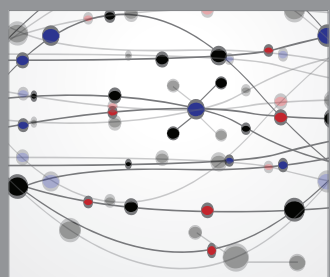

The Scientific World Journal
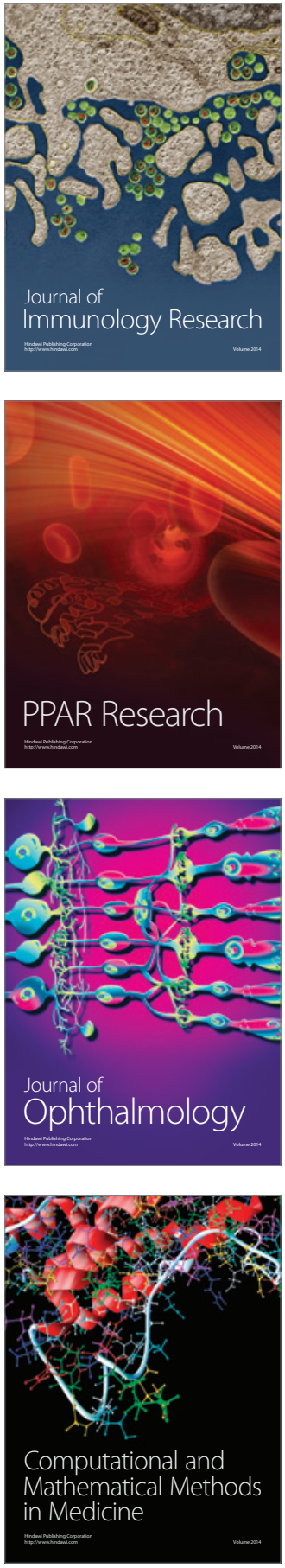

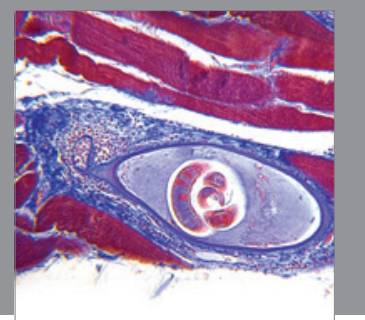

Gastroenterology

Research and Practice
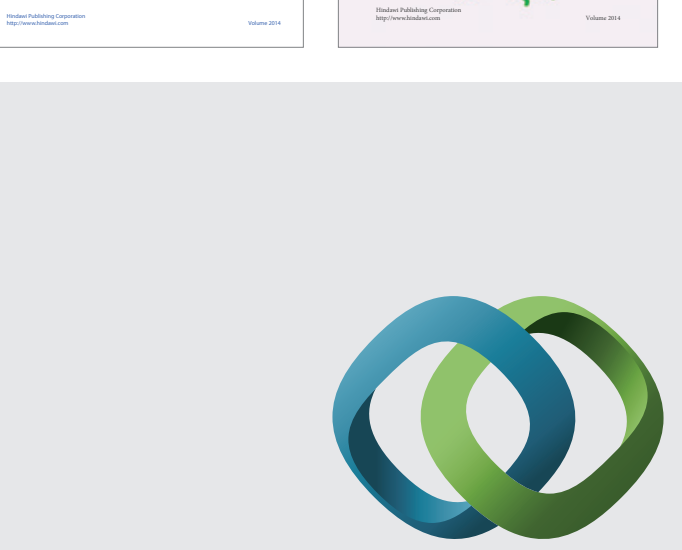

\section{Hindawi}

Submit your manuscripts at

http://www.hindawi.com
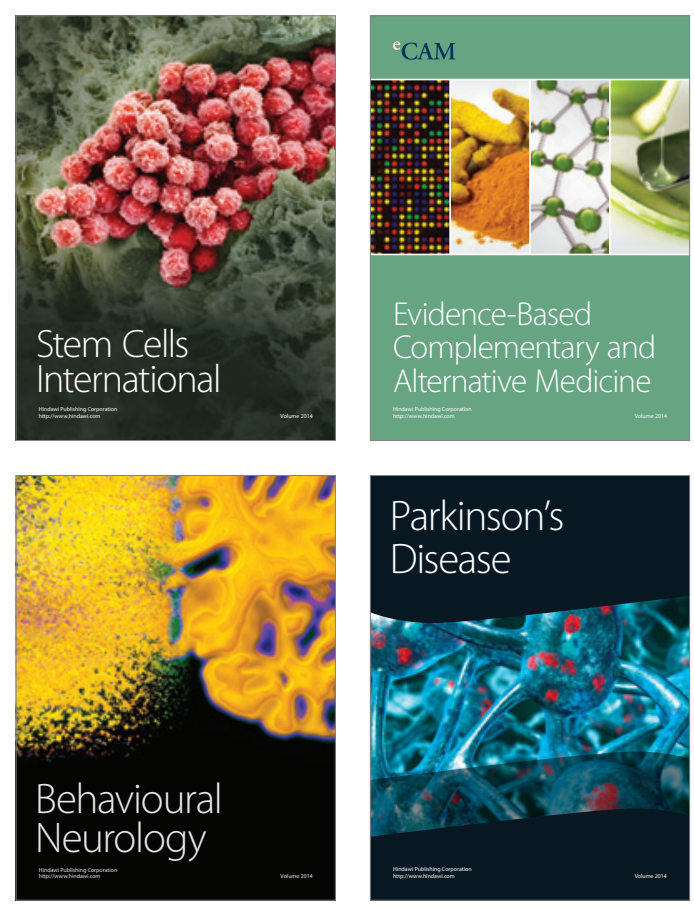

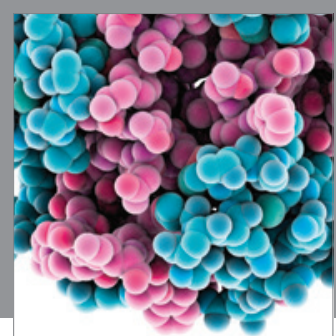

Journal of
Diabetes Research

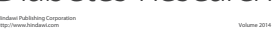

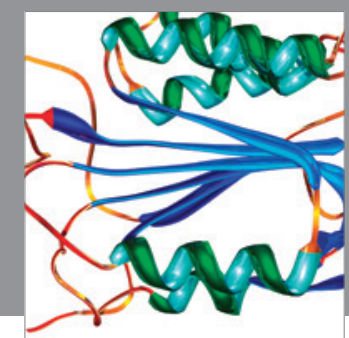

Disease Markers
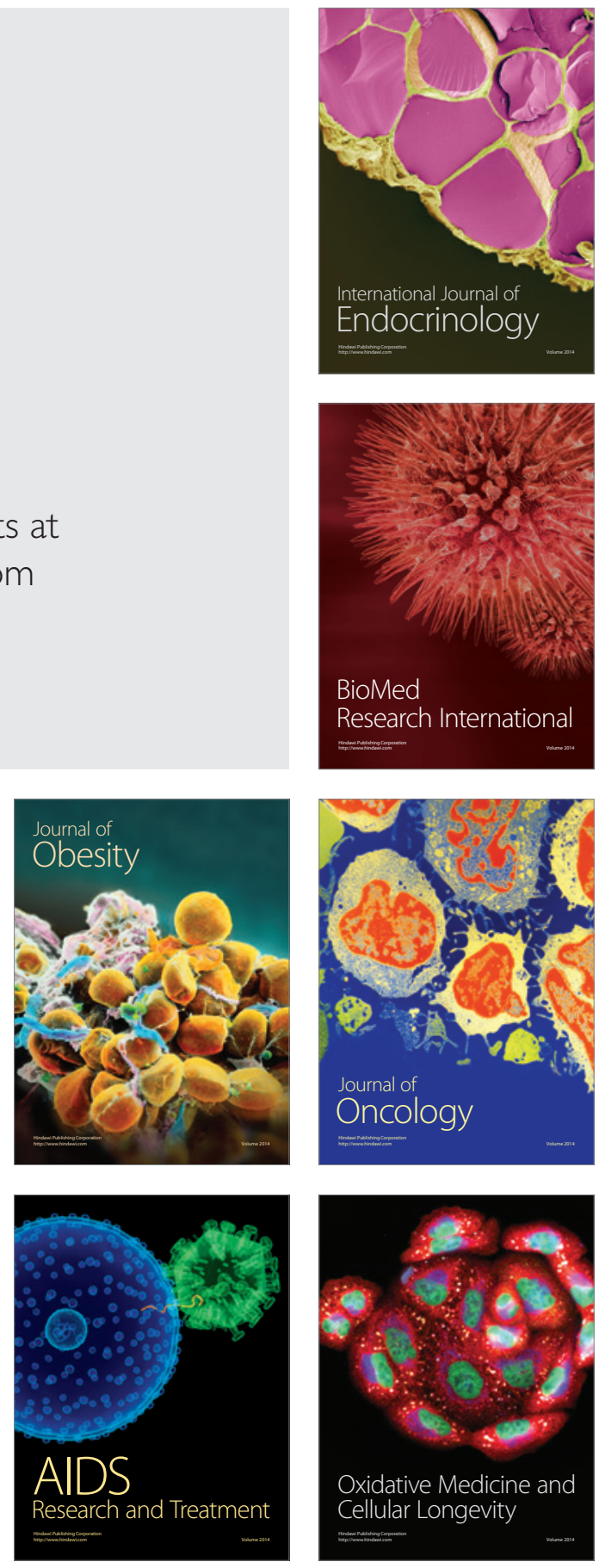